\title{
Role of ECMO in neonatal myocardial infarction
}

\author{
Andrew J P Tometzki, James C S Pollock, Neil Wilson, Carl F Davis
}

The Royal Hospital for Sick Children, Yorkhill NHS Trust, Dalnair Street, Glasgow G3 8SJ

Department of Cardiology and Cardiac Surgery A J P Tometzki J C S Pollock $\mathrm{N}$ Wilson

Department of Paediatric Surgery C F Davis

Correspondence to: Mr Carl F Davis.

Accepted 11 August 1995

\begin{abstract}
A neonate with myocardial infarction who failed to respond to conventional treatment was supported by extracorporeal membrane oxygenation (ECMO). Severe mitral valve regurgitation necessitated mitral valve replacement while receiving ECMO following which the infant was successfully weaned.
\end{abstract}

ECMO should be considered for potentially treatable causes of catastrophic heart failure.

(Arch Dis Child 1996; 74: F143-F144)

Keywords: ECMO, myocardial infarction, mitral valve.

\section{Case report}

A 9 day old boy, weighing $2.9 \mathrm{~kg}$, presented with poor feeding and signs of heart failure with tachycardia, tachypnoea, and hepatosplenomegaly. Pregnancy and the perinatal period were uneventful.
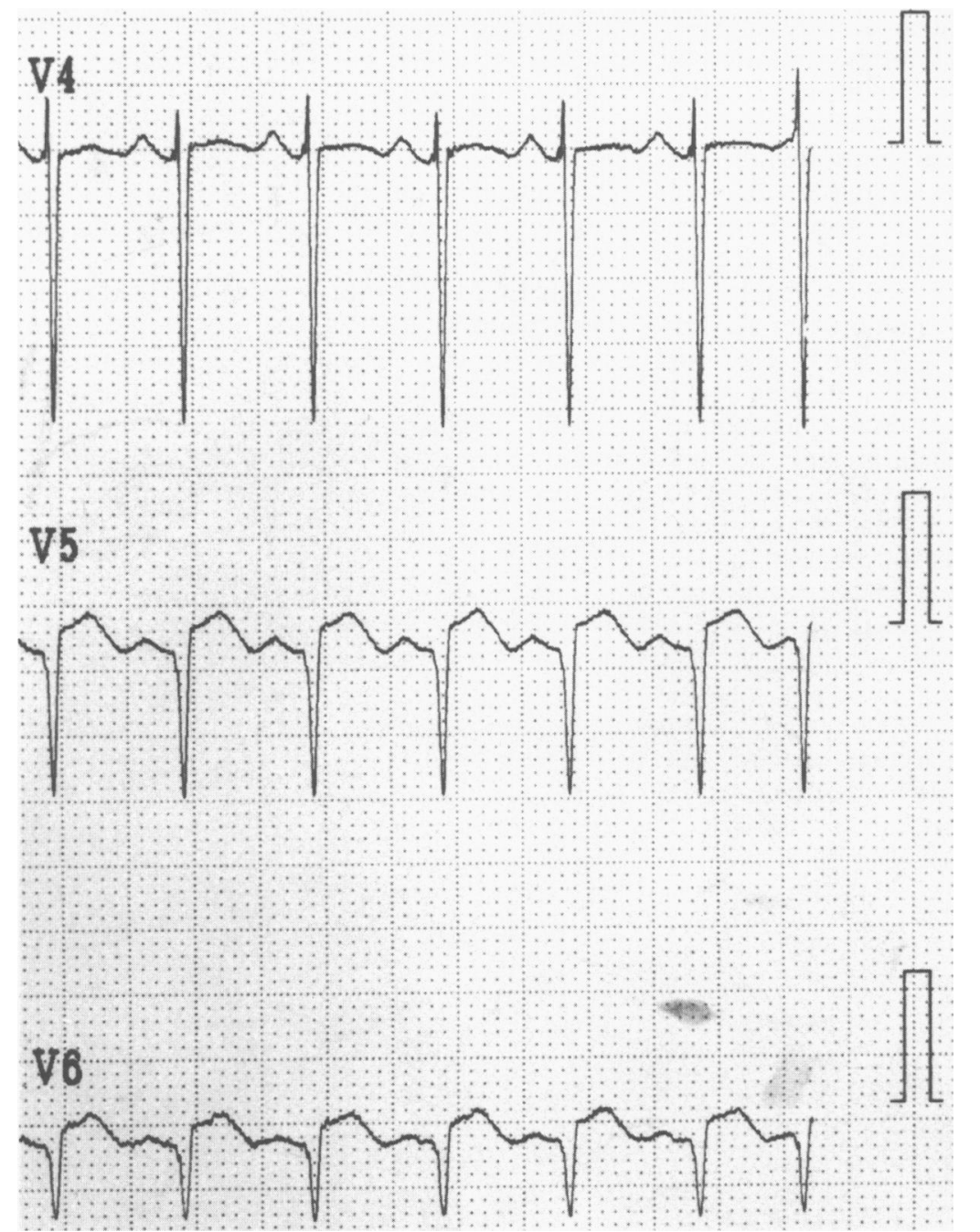

Figure 1 Electrocardiogram, precordial leads $V_{4}-V_{6}$, showing myocardial infarction.

Full blood count on admission revealed neutrophilia $\left(24.5 \times 10^{9} / 1\right)$ and thrombocytopenia $\left(23 \times 10^{9} /\right)$. An electrocardiogram (ECG) showed extensive posterolateral myocardial infarction (fig 1). Creatine kinase was 663 IU// (normal $<230 \mathrm{IU} / \mathrm{l}$ ) on the day of admission.

Echocardiography showed that the left ventricular posterior wall and apex were akinetic. $\mathrm{M}$-mode quantified the fractional shortening at $22 \%$ (normal $>28 \%$ ) (fig 2 ). Coronary artery anatomy and patency could not be adequately ascertained but a ductus arteriosus was identified. A coagulation profile, protein $\mathrm{C}$, protein $S$ and antithrombin III concentrations were within normal limits as were the same indices in both parents. Screening for congenitally acquired infections including Coxsackie B virus were negative. Anticardiolipin antibody (IgG, $\operatorname{IgM}$, or $\operatorname{IgA}$ ) was not identified in the serum.

Initial digitalisation was replaced by flecainide $(2 \mathrm{mg} / \mathrm{kg}$ twice daily) for multiple episodes of ventricular and supraventricular tachyarrhythmias. Seventy two hours after admission he became cyanosed and increasingly tachypnoeic, requiring intubation and ventilation. Cardiac catheterisation was undertaken which indicated normal coronary artery anatomy and a ductus arteriosus. Pulmonary artery pressure was measured at $90 / 55 \mathrm{~mm} \mathrm{Hg}$ (mean $62 \mathrm{~mm} \mathrm{Hg}$ ) and aortic pressure $55 / 48 \mathrm{~mm} \mathrm{Hg}$ (mean $50 \mathrm{~mm} \mathrm{Hg}$ ). Following catheterisation the infant's condition rapidly deteriorated with catastrophic cardiac failure and severe metabolic acidosis.

Veno-arterial ECMO was established following emergency cannulation of the right carotid artery and right internal jugular vein using Biomedicus cannulae, 8 and 10 French gauge, respectively. Bypass flows were increased to $125 \mathrm{ml} / \mathrm{kg} /$ minute. Ventilator 'rest' settings were instituted. Activated clotting times were maintained between 170 and 190 seconds. Blood products were used to keep the platelet count above $120 \times 10^{9} /$, and to maintain a haematocrit of $40-45 \%$. Multiple dysrhythmias continued over the first 48 hours of the ECMO course and were controlled by intravenous amiodarone (15 mg/kg/day).

Cardiac stun ensued once veno-arterial ECMO was begun. M-mode measurements of left ventricular (LV) function showed a fractional shortening as low as $5 \%$. After seven days, bypass flows were weaned to 60 $\mathrm{ml} / \mathrm{kg} / \mathrm{minute}$ and improved function could be seen on two dimensional echocardiography. Attempts to wean from ECMO support at this time were unsuccessful, because of intermittent massive mitral regurgitation inducing pulmonary oedema, caused by papillary muscle dysfunction. 


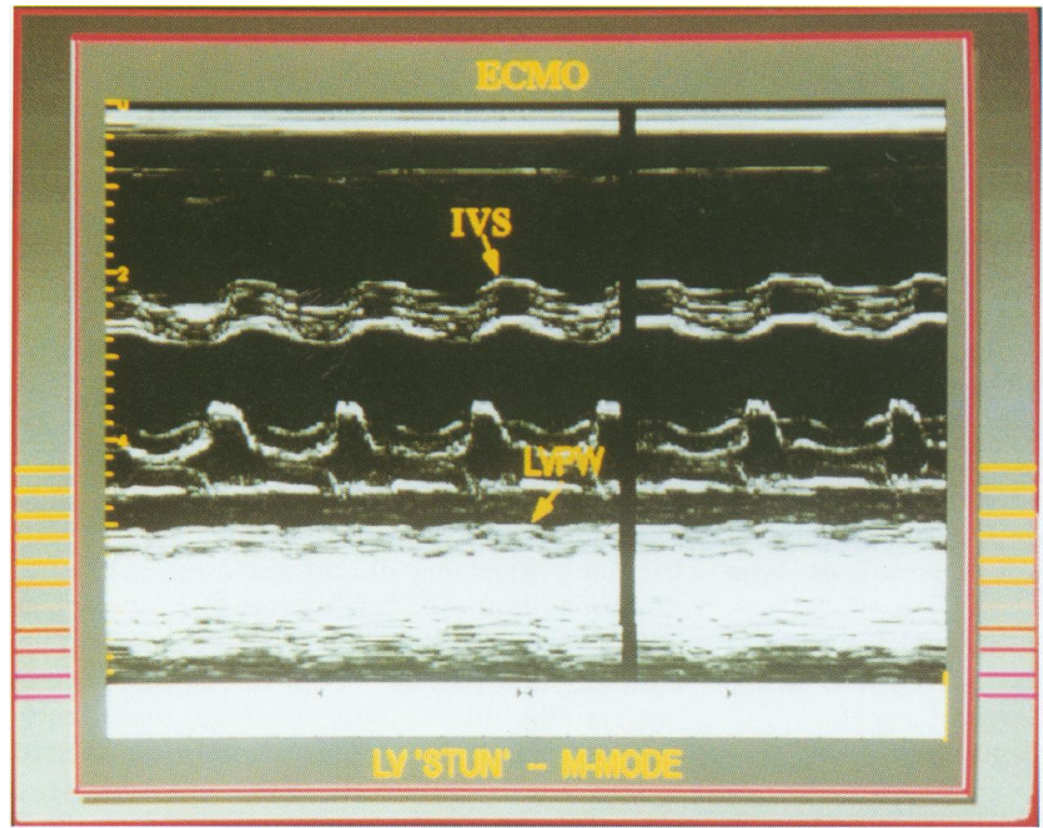

Figure 2 M-mode echocardiogram showing cardiac 'stun', where IVS is the interventricular septum and LVPW is the left ventricular posterior wall.

After 241 hours of ECMO support the mitral valve was replaced with a $16 \mathrm{~mm}$ Carbo Medics bileaflet prosthesis. Surgery was performed in the intensive care unit via a left lateral thoracotomy, having established conventional operative cardiopulmonary bypass using the ECMO cannulae already in situ, with cooling to $20.5^{\circ} \mathrm{C}$ and 25 minutes of circulatory arrest. Normothermic ECMO support was re-established postoperatively and an aprotinin infusion was continued to aid haemostasis. Drainage of a large left haemothorax was necessary 68 hours postoperatively, following which ECMO support was successfully discontinued after a total of 351 hours. Withdrawal of ventilatory support was accomplished after a further 18 days. He was discharged home aged 8 weeks, feeding orally and with an improved fractional shortening of $18 \%$ receiving low dose aspirin, diuretic, and captopril. This was subsequently changed to warfarin following an episode of prosthetic valve thrombosis that was successfully treated with a thrombolytic. He remained well at 1 year of age at the time of writing.

\section{Discussion}

Neonatal myocardial infarction is rare and mortality approaches $90 \% .^{12}$ Kilbride et al reviewed 15 cases and suggested that thromboembolic events as the most common cause. ${ }^{1}$ They postulated paradoxical thromboembolism from thrombus within the umbilical venous system, possibly associated with umbilical venous catheterisation. In four of the 15 cases a cause was not identified. Boulton and colleagues reviewed 16 cases. $^{2}$ All but three (presenting between 13 and 17 days) were symptomatic within several hours of birth and four had documented fetal distress, suggesting a close correlation with perinatal asphyxia. The three 'late' myocardial infarctions survived, but only one out of 13 presented early. This patient had no known perinatal asphyxia nor had he undergone umbilical venous cannulation. Rare causes of myocardial infarction in this age group include clotting disorders such as antithrombin III deficiency. ${ }^{3}$ We were unable to show any abnormality of the clotting cascade in our patient.

Cardiac catheterisation and angiography in an ill neonate is risky. This was performed primarily to determine coronary anatomy. The ECMO circuit was primed before cardiac catheterisation. This facilitated rapid placement on ECMO support when his condition suddenly deteriorated at the end of the procedure.

The valve was replaced because of severe annular dilatation, cusp prolapse, and papillary muscle dysfunction. A bileaflet prosthesis enabled a supra-annular placement with unrestricted leaflet mobility. Experience shows that the prosthesis will need to be replaced at 5 to 6 years of age as the child will have grown.

ECMO is an accepted rescue treatment in severe neonatal respiratory failure in the USA. The role of neonatal ECMO in the United Kingdom is currently being assessed in a collaborative, prospective randomised controlled trial of ECMO vs more conventional management. Veno-arterial ECMO provides excellent cardiac support. ${ }^{4}$ This case identifies a role for ECMO as a salvage procedure in acute, catastrophic myocardial failure where functional and anatomical assessment indicates potential for recovery.

1 Kilbride H, Way L, Merenstein G, Winfield J. Myocardial infarction in the neonate with normal heart and coronary arteries. Am $\mathcal{F}$ Dis Child 1980; 134: 759-62.

2 Boulton J, Henry R, Roddick LG, Rogers D, Thompson L Warner G. Survival after neonatal myocardial infarction. Pediatrics 1991; 88: 145-50.

3 Peeters S, Vandenplas Y, Jochmans K, Bougatef, De Waele $M$, De Wolf D. Myocardial infarction in a neonate with hereditary antithrombin III deficiency. Acta Paediatrica 1993; 82: 610-13

4 Levy F, O'Rourke P, Crone R. Extracorporeal membrane oxygenation. Anesth Analges 1992; 75: 1053-62. 